\title{
Challenging the Pedagogy of Tertiary Level Horticulture
}

\author{
Bruce R. M acK ay, ${ }^{1}$ \\ Lisa Emerson, ${ }^{2}$ \\ Marion B. M acKay, ${ }^{1}$ \\ Keith A. Funnell, ${ }^{1}$ and \\ T. Eddie Welsh ${ }^{1}$
}

AdDITIONAL INDEX WORDS. teaching methods, transferrable skills, writing across the curriculum, lifelong learning

Summary. M ajor reform of the undergraduate degree program in the Faculty of Agricultural and $\mathrm{H}$ orticultural Sciences at M assey U niversity has resulted in greater emphasis being placed on developing attributes of lifelong learning in our students. T ranslating this particular goal into transparent educational practice in the horticulture courses required us to overturn the existing teaching paradigm. The traditional contentfocused, principles first, integration second strategy of the existing horticulture curriculum was replaced at the $\mathbf{1 0 0}$ level by a new course that melded the discipline of horticulture with attributes needed for lifelong learning. $U$ sing action learning strategies, principles of horticulture were presented in context, with students encouraged to apply and analyze them in the wholeness of the discipline. Students critically reflected on their experiences through writingto-learn exercises, class or group discussion, oral presentations, and experientially through their laboratories. By incorporating our students' experiences with these strategies, we successfully achieved our goal of the students' learning and relating the

We thank Alison Duffy for her assistance with the sunflower project, Ray Johnstone and his staff at the Plant Growth U nit for maintaining the plant production systems, and $\mathrm{L}$ uke $\mathrm{H}$ ansen for his tutoring in the laboratories. The cost of publishing this paper was defrayed in part by the payment of page charges. U nder postal regulations, this paper must be hereby marked advertisement solely to indicate this fact.

${ }^{1}$ D epartment of Plant Science, $M$ assey U niversity, Private Bag 11222, Palmerston N orth, N ew Zealand.

${ }^{2}$ Business Studies Writing Center, M assey U niversity, Private Bag 11222, Palmerston N orth, N ew Zealand. 
principles of horticulture to the whole discipline. Although the students understood our goals in engaging them in writing-to-learn and group activities, they did not appear to recognize the educational processes in which they participated throughout the course. It seems that in forming the foundation for lifelong learning in applied science, greater attention must be given to making our mental models of the education process more transparent to the students.

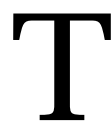

he recent emergence of the ethos of students as clients of higher education has stimulated major curriculum changes such as those undertaken by the Faculty of Agricultural and $\mathrm{H}$ orticultural Sciences at $M$ assey U niversity. Key goals of these reforms include a commitment to developing independent learning skills, promoting the ethos of lifelong learning, providing flexibility for students to design and take greater responsibility for their own learning, catering to a wide range of preentry backgrounds, abilities and career development interests, and emphasis on the underlying principles and integrated nature of natural resource, food, and fiber systems (Anderson, 1995). Importantly, these goals reflect the increasing employer demand for graduateswith developed skillsin communication, problem-solving, team learning, entrepreneurship, interpersonal relations, and lateral thinking (Anderson, 1995).

For our faculty, these goals represented a major departure from the traditional teaching paradigm that emphasized discipline-orientated topics. As a consequence, a new style horticulture course was designed to address the wider goals of the curriculum reforms. Thispaper describessome of thestrategiesused in the new course, presents results from the focus groups organized to provide feedback on the paper from the students, and reflects on those areas where further improvement or more emphasis is required.

$\mathrm{H}$ orticulture I is a double-semester, 15-point course (equal to two 4credit single-semester courses) offered at the 100 level (first year) of the 3-year Bachelor of A pplied Science (BA pplSc) program. The course was first offered in 1995 with 47 of an initial enrolment of 51 students completing the course. Its teaching team comprises staff from the D epartment of Plant Science with experience in $200^{+}$level horticulture teaching and laboratory instruction, and an outsider from the faculty of Business Studies' Writing Center with experience in action research and a research interest in writing across the curriculum. The development, delivery and ongoing management of the course have been run, since its inception (M acKay, 1994), under the auspices of an action research program (C arr and Kemmis, 1986).

Observation is a major component of action research. Action research promotes triangulation of observation techniques (Bunning, 1994; Kemmis and M CTaggart, 1990; Selener, 1997), and this was achieved through the maintenance of staff journals, the university's Student Evaluation of Teaching review process, and student focus groups (K rueger, 1988; Robson and Foster, 1989). O ne nonteaching member of the team coordinated the evaluation and observation methods, directed the focus of staff journals and conducted the focus groups. Focus groupswere conducted three times throughout the academic year using questions generated by the teaching team and randomly selected students whose identities were kept from the teaching staff.

O ur desire to develop an ethos of lifelong learning in our students, rather than solely teach them about horticulture, was explicitly stated in our mission, goals, and objectives. This was an important milestone for the teaching staff. It clearly affirmed our commitment to directly assist our students in developing important attributes of lifelong learning, rather than leaving these to be acquired as a by-product of the students' educational endeavors, as is often the case (Anderson, 1995).

Asa discipline and at the very core, horticulture integrates principles of chemistry, biology, mathematics, art, and business management. U nder the traditional paradigm employed by our department, studentsreceived agrounding in these so-called "principles of horticulture" before the integrative nature of the discipline was taught. H owever, student performance under this paradigm indicated that theseprincipleswere not learned and the ability of studentsto integrate was inadequate. We conjectured that three characteristics of the existing instructional paradigm contributed to these problems.
First, the "principles first, integration second" approach removes an opportunity for extending the cognitive skills of the students. Relative to Bloom's taxonomy of educational objectives (Bloom, 1956), the types of assignment and examination questions that accompany a "principles first" course rarely requirelevels of cognitive skill development greater than knowledge and comprehension.

Second, a major weakness of teaching horticultural principlesisthat they are frequently presented without an associated framework (i.e., out of context). Although the lecturer is well aware of how the threads of principles eventually form the tapestry of horticulture, such awareness is rarely or poorly translated to the students. This makes it difficult for them to see the structure of knowledge(Gibbs, 1992), simply put, how the piecesfit together, resulting in isolated, poorly learned principles. In addition, students do not gain experience at constructing the whole from its parts and lose the opportunity for developing higher order cognitive skills (e.g., application, analysis, synthesis and evaluation; Bloom, 1956).

Third, the "principles first, integration second" approach sets unrealistic expectations for both students and teachers. The approach implies that students can be taught all the principlesthey will ever need to knowthis, of course, is simply not possible. With theincreasing complexity of horticultural technology and scientific methodology (Cantliffe, 1995; Corbett, 1992), we cannot hope to give students a firm understanding of all the principles of these disciplines as they relate to horticulture. Instead, our students should learn how to learn and take personal responsibility for their learning. Furthermore, as postuniversity learning will occur on a "need-to-know" basis(i.e., the educational equivalent of the business " justin-time" inventory control paradigm; DuBrin et al., 1989), our students must be flexible in their approaches to learning.

The strategies we used to achieve our objectives were developed in response to the opportunities apparent in the new philosophy of the BApplSc program. We agreed that the traditional teacher-centered, lecture-based strategy subordinated the learning opportunity to knowledgetransfer (i.e., 
from the lecturer to the students), and encouraged passive learning ( $\mathrm{J}$ ackson and Prosser, 1989; Liow et al., 1993) and rote memorization rather than critical thinking ( $M$ oss and M CM illen, 1980). M oreover, the tendency of the traditional strategy to promote competition rather than cooperation, while failing to instill the ethos of lifelong learning (Chiodo et al., 1991), conflicted with the educational goals of our faculty. Our learning strategies were strongly influenced by Kolb's learning cycle (Kolb et al., 1979) and action learning methodology (ZuberSkerritt, 1993); i.e., after experiencing and identifying a problem, a cycle of observation and reflection, conceptualization and generalization, and action to validateisfollowed. Wherever possible, weengaged thestudents in motivating activities. Brainstorming, mind-mapping (H ogan, 1994), reviewing assigned readings, and inclass writing exercises kept the students engaged in the learning process during lectures. We provided the studentswith experiences(e.g., field trips, laboratories, readings), and asked them to critically reflect on those experiencesthrough writing, discussion, trial and error in their laboratory projects, and learning from each other.

A major vehicle of our action learning approach wasthesunflower project. This double semester project was designed to give the students experience in the integrated management required of a professional horticulturist. G roups of five to seven students were allocated greenhouse space and given the scenario of being a firm of horticultural consultants employed by a cut flower producer interested in producing sunflowers ( $\mathrm{H}$ elianthus annuus L.) during winter. Their brief was to define market needs, determine the best time for production to occur, and develop a production plan that thegrower could follow to reach this goal. Students had to interview local florists, raise seedlings in various media, calculate crop profitability, manage plant nutrition, monitor pests and diseases, schedule crop production, harvest flowers, and follow their progress through the market chain. Students experienced team dynamics, communicated to grower audiences, and collected, analyzed, and presented data. Thestudents grew several cycles of the crop throughout the year, making adjustments to their production techniques based on previous experiences and an expanding knowledge base.

Most notably, the sunflower project initially provided studentswith only a framework-developing the project within the framework was the responsibility of each group. To induce the students to use their own initiative, weprovided minimal instruction throughout the project. The project was started 7 weeks before the students received any lectures on production horticulture, compelling them to use the skills and experiences from within their group to get their first crop cycleunderway. An aphorism used by one of uswhen outlining the project to the students: "We won't teach you to swim until you are in the water" succinctly encapsulated our approach. We tried not to intervene whenever we saw the students making mistakes in producing their crops, preferring to encourage them to reflect on the consequences and to learn from them. It took some time for the students to realize that mistakes would go unpenalized, and with this came an increased desire to try different sunflower production techniques.

Student response to the project was positive and wide ranging. For some, it wastheir first prolonged experience in growing crops: "I enjoyed the practical, the whole work of the sunflowers because I had never done plant stuff before, never grown anything using horticultural methods... It's just doing the work, the organization and stuff like that ...". Others appreciated the wider goals of the project - " ... and you really learnt heaps about how to negotiate tasks and how to pick out what people are good at, work like that..."; its educational value- "Was this different to being told?": "H eck yeah. Doing it practically yourself, it'sjust like making your own mistakes rather than being told, you find out personally-that's better ..."; and the wholeness of the discipline- "... And also, when you've got a business in horticulture and how things can go wrong-how the environment can affect your profits-but also how the market can affect it as well."

Focus groups identified two major benefits of using the students' previous horticultural experiences as part of the lecture and project activities. First, directing specific questions to students who had appropriate experi- ence made them communicate and share their experiences. The students' self esteem and confidence were raised, as the lecturer was acknowledging, as one student noted "... that you know stuff." Second, although the conversation was one-on-one, the rest of the class saw confirmation of the point the lecturer was making by way of the example; as one student responded: “... and we could see-oh right, it actually does work and there is a real life example of it." As N ightingale and O 'N eil (1994) also point out, thistype of interaction with the class also has other benefits to learning. The students' communication skills are enhanced (Emerson, 1998) and their confidence in talking to large groups increased. Their understanding of the subject is also increased because in formulating an answer, they arehaving to reflect upon and reevaluate prior knowledge and experience in light of the information just provided by the lecturer. For the class, the interaction is an opportunity to develop critical listening skills.

But just as prior experiences are important in the process of learning, they can also form barriers (Boud and Walker, 1993). Prior experiencesform the basis of the deeply held images, our mental models (Senge, 1990), that actively shape the way we perceive our world. I is likely that if students do not share the same mental model of a university education as their teachers, then learning strategies will fall short of their intended goals. H ence, while our mental model of the course was to train horticulturists by melding the discipline of horticulture with the attributes needed for lifelong learning, it is possible that our students' mental models were quite different. For example, transcripts of focusgro up meetings at the completion of the course revealed that, despite their realized experiences in communication, team learning, information processing, and interpersonal management throughout the course, somestudents only saw the course offering the discipline of horticulture (albeit an integrated view of the discipline):

Facilitator: $C$ an we talk about the focus of the [course] - if you had to sum up, what would you say the [course] was about?

Student A: I think that now we're doing reportswecan understand- 
we are trying to explain how it [the sunflower crop] illustrates horticulture to a [high school] class. ... But you can see howwhatever you choose it would apply anywhere. I think we' ve possibly learnt more about cut flowers ... like, I'll get to the end of this course and I won't know much about orcharding, but I will know about the principles-they, they apply to everywhere.

Facilitator: I fyou weretalking to anew student [next year] who was considering taking the [course], what would you say?

Student A: I'd say that you learn about horticulture-like $\mathrm{H}$ orticulture I talks about a whole production horticulture and as they go they talk about irrigation and photosynthesis. H orticulturel - they say "I'm going to teach you about horticulture" not "I'm going to teach you about irrigation, media..."

Student B: I 'd just say it'safoundation [course] for if you're doing production horticulture-it's a principle [ course], you' re learning the principles of landscaping, of protected cropping, principles of soils, of irrigation ...

Similarly, although we planned our teaching strategies around Kolb's learning cycle (Kolb et al., 1979), we did not explain or introduce the students to models of learning. Thus, when students in the focus groups were asked about the value of the writing-to-learn exercises, one replied, “They don't al ways seem to serve that much of a purpose except to back up what we've just done that week." Of course, self-reflection was one of the objectives of the writing-to-learn exercises. That such an answer was forthcoming raises the possibility that, had the student been made aware of the importance of reflection to the learning process (apparently reflection did not assume any significance in the student's mental model of learning), then the purpose of the exercises may have assumed more importance for that student (and, presumably, for other students). Perhaps it is not only educators who overemphasize course content at the expense of education (Anderson, 1995). Perhaps students, still working from old paradigms, do not recognizetheprocess of education or its value to their professional career ambitions.

$M$ aking theeducational processes more transparent to the students may help them better set their own learning priorities, and in doing so, assume greater responsibility for their own learning. This, in turn, may circumvent problems of assessment. For example, we found the need to assessour students' performance often clashed with our desire to have them take greater responsibility for their own learning. O n one hand, we recognized that thestructure of assessment greatly influences student learning responses (Barr and H ealy, 1988; Gibbs, 1990; H eywood, 1989; $M$ arton and Säljö, 1976) and if we did not assess all facets of our objectives as being important, then our students would neither accept, nor develop towards, these outcomes. On the other hand, in promoting in our students a sense of individual responsibility for their own learning, we were reluctant to provide the extrinsic motivation of grades for every piece of work.

Setting up an assessment structurethat reflected the course's emphasis on group work, principle integration, numeracy and communication skills was not difficult. Each student's performance within the group was peer-assessed, and individual performance was assessed through oral presentations, journal writing, and examinations. As information management was an important skill, the examinationswere open-book and consisted of questions that tested reasoning and understanding, and required students to write to specified audiences. I n contrast, assessing the extent to which students took responsibility for their own learning was more difficult. We did not allocate grades to assess laboratory reports of field and greenhouse exercises, yet the subject material covered in the exercises was made examinable. We explained to thestudentsthat although it was in their best interest to complete the work, the final decision would be left to them. $M$ any students handled thisresponsibility poorly, with many of the reports not completed. As a result, the deeper lesson of taking greater self-responsibility for learning was probably neither recognized nor learned.

$\mathrm{H}$ orticulture is an interaction among people, plants and theenvironment, with theenvironmental response of plants based on principles of chemistry, mathematics, biology, genetics and plant physiology. Students need a basic understanding of these principles to be able to derive applications by reason, rather than memory (Rogers, 1990). But teaching principles in the absence of application develops and rewards memory skills at the expense of reasoning skills. M oreover, it issimply not possible to teach our students all the principles they will need in their horticultural careers. In seeking to improve existing horticultural products and practices, they will have to seek and use new information. They will have to return to the literature, learn or revise the principles relevant to the current topic, and with insight and innovation, use their understanding of these principles to synthesize new solutions. In turn, introducing these solutions in practice will require skills of leadership, teamwork and communication.

O ur paradigm, and our approach to teaching it, may potentially provide our students with the abilities to meet thesechallenges. M oreemphasis, however, must be placed on aligning the students' mental model of a higher education with the educational processes we have employed in the delivery of the paradigm. Wecannot expect to instill the ethos of lifelong learning in our students in a single year-our paradigm needs to be extended throughout thestudents' undergraduate program. The pedagogical principles by which this paradigm was presented need to be developed and further explored. Fortunately, thisisstarting to occur in our department. $\mathrm{N} \mathrm{ew}$ 200 and 300 level courses will follow the same paradigm, and we expect that as other colleagues become involved with the approach, they will experience the same transformation as we had. Certainly, our own approachesto teaching havebeen irrevocably changed by our involvement in $\mathrm{H}$ orticulturel, and a ripple effect isal ready apparent in other courses as others perceive the benefits of this approach. Challenging the process of education in our horticulture program has been an empowering experience. For our students, it has been an experience that has promoted their understanding and ownership of the nature of horticulture. O ur next task is to challenge their mental models and thereby extend this empowering experience. 


\section{Literature cited}

Anderson, R.D. 1995. Science, technology and education-Thechallengeto education. Agr. Sci. 8:37-40.

Barr, M .A. and M.K. H ealy. 1988. School and university articulation: different contexts for writing across the curriculum, $p$. 43-53. I n: S.H. M cL eod (ed.). Strengthening programs for writing across the curriculum. $\mathrm{N}$ ew D irectionsfor T eaching and Learning N o. 36. J ossey-Bass, San Francisco.

Bloom, B.S. (ed.). 1956. Taxonomy of educational objectives: The classification of educational goals. $\mathrm{H}$ andbook I: Cognitive domain. D avid M cKay, N ew York.

Boud, D. and D. Walker. 1993. Barriersto reflection on experience, p. 73-86. In: D. Boud, R. Cohen, and D. Walker (eds.). $U$ sing experience for learning. Soc. Res. into $\mathrm{H}$ igher Educ., Open Univ. Press, Buckingham, England.

Bunning, C. 1994. Action research: An emerging paradigm. Tertiary Educ. Inst. O ccasional Papers Ser. 4. Tertiary Educ. Inst., U niv. Queensland, Brisbane, Q ueensland, Australia.

Cantliffe, D.J. 1995. Challenges facing horticulture in a changing world. H ortScience 30:1339-1340.

Carr, W. and S. Kemmis. 1986. Becoming critical: Education, knowledge and action research. Falmer Press, L ondon, England.

Chiodo, G., W. Bullock, H. Creamer, and D. Rosenstein. 1991. An application of the patient-orientated problem-solving (POPS) system. J. D ental Educ. 55:327331.

Corbett, E. 1992. Some potential problems facing horticulture. Hort. I mpact (M arch)6-7.

DuBrin, A.J., R.D I reland, and J.C. Williams. 1989. M anagement and organization. South-Weston Publishing Co., Cincinnati, O hio.

E merson, L.E. 1998. Writing-across-thecurriculum in a $\mathrm{N}$ ew Zealand tertiary context. PhD diss., M assey U niv., Palmerston N orth, N.Z.

Gibbs, G. 1990. I mproving student learning project: Briefing paper. Oxford $\mathrm{Ctr}$. Staff Dev., Oxford Polytechnic, Oxford, England.

Gibbs, G. 1992. I mproving the quality of student learning through course design.
In: R. Barnett (ed.). Learning to effect. Soc. Res. into $\mathrm{H}$ igher Educ., O pen U niv. Press, London, England.

H eywood, J. 1989. Assessment in higher education. 2nd ed. Wiley, $\mathrm{N}$ ew York.

Hogan, C. 1994. M ind mapping: Some practical applications. Training M gt. D ev. M eth. 8:3.01-3.18

Jackson, M.W. and M.T. Prosser. 1989. Less lecturing, more learning. Studies $\mathrm{H}$ igher Educ. 14:55-68.

Kemmis, S. and R. M cT aggart, 1990. The action research plan. 4th ed. D eakin U niv. Press, Geelong, Australia.

Kolb, D .A., I.M . Rubin, and J.M . M cl ntyre. 1979. Organisational psychology: An experiential approach. 3rd ed. Prentice H all, Englewood Cliffs, N.J .

Krueger, R.A. 1988. Focusgroups: A practical guide for applied research. SAGE Publ., N ewbury Park, Calif.

Liow, S.R., M . B etts, and J. Lok Leong Lit. 1993. Course design in higher education: a study of teaching methods and educational objectives. Studies H igher Educ. 18:65-79.

M acK ay, B.R. 1994. $71.122 \mathrm{H}$ orticultural technology: Structure and delivery. D ept. Plant Sci., M assey U niv.

M arton, T. and R. Säljö. 1976. O utcomes as a function of the learner's conception of the task. Brit. J. E duc. Psychol. 46:23-29.

Moss, G.D. and D. M cM illen. 1980. A strategy for developing problem-solving skills in large undergraduate classes. Studies $\mathrm{H}$ igher E duc. 5:161-171.

Nightingale, P. and M. O'N eil. 1994. Achieving quality learning in higher education. Kogan Page, London.

Robson, S. and A. Foster. 1989. Q ualitative research in action. Edward Arnold, London.

Rogers, M.N. 1990. Teaching philosophy and techniques. H ortScience 25:730-731.

Selener, D . 1997. Participatory action research and social change. Cornell Participatory Action Res. N etwork, I thaca, N .Y.

Senge, P.M. 1990. The fifth discipline. D oubleday, $\mathrm{N}$ ew York.

Zuber-Skerritt, O . 1993. I mproving learning and teaching through action learning and action research. $\mathrm{H}$ igher $\mathrm{Educ}$. Res. Dev. 12:45-58. 